\title{
ETDCC: Energy-Efficient Transmission Scheme for Dynamic Climatic Conditions in WSN
}

\author{
Sunil Kumar*, Prateek Raj Gautam, Tarique Rashid, Akshay Verma, and Arvind Kumar \\ Motilal Nehru National Institute of Technology Allahabad (211004) India \\ *Corresponding Author, email: rel1516@mnnit.ac.in
}

\begin{abstract}
In this paper, an energy-efficient transmission scheme for dynamic climatic conditions (ETDCC) has been proposed in wireless sensor networks (WSNs). This scheme is based on IEEE802.15.4 standard. In this method, open-loop and closed-loop feedback systems are used for snowfall variation. An open-loop system is utilized for snowfall-aware link quality compensation and estimation. However, closed-loop system aids to split the network into two logical regions, resulting the overhead of total control packets is minimized. According to link quality changes due to snowfall variation, the transmitting power is decided on the basis of current number of neighbor nodes and threshold power loss for each region. The simulated results depict that the proposed scheme with reduced control packets overhead adjusts transmitting power level $\left(P_{\text {level }}\right)$ to compensate link quality. This scheme based on threshold level is compared with the conventional approach that comprises the division of regions without threshold level.
\end{abstract}

Keywords: Energy-efficient; snow; transmitter power; link quality; WSNs.

Copyright (C) 2018 Universitas Ahmad Dahlan. All rights reserved.

\section{Introduction}

Energy is an important aspect in the design of WSNs. In order to transfer data without difficulty over wireless channels in WSNs, an adaptive approach is used for data transmission to set the lowest transmitting power and maintain reliability. This approach either diminish unnecessary power consumption or interference among the nodes. To tune power level transmission, a beacon message is sent periodically through reference node to receiving node and respectively acknowledgment(ACKs) is back to the reference node for sending data. Through these interaction, the reference node retain connectivity among the nodes [1, 2].

An algorithm, known as Local Mean Algorithm (LMA), is used by the reference node to broadcast the LifeMsg message. This message is transmitted by the neighbor nodes after receiving the LifeMsg. Reference node calculates all LifeACKMsg and sets the transmitting power to maintain proper connectivity. If LifeACKMsg is more than NodeMaxThresh, transmitting power is decreased. In contrast, if LifeACKMsg is less than Node MaxThresh, the transmitting power is increased by the reference node. Through this approach, the network lifetime improvement is obtained sufficiently, but LMA estimates only connectivity among the nodes and cannot provide acknowledgment about link quality $[3,4]$.

Stability of network based on lifetime is one of the major challenge for WSNs. An scheme is proposed to estimate transmitter power level. Transmitter power is also controlled by the deployment of node in the proper place to lessen the distance for communication [5].

Since loss is directly related to environment variation, an adaptive transmission power control is used according to spatial and temporal effects. This scheme helps to acclimate link quality according to variations by closed-loop feedback. Whereas it is very difficult to support large WSNs due to the creation of overhead that is required to adjust transmitting power of each establishing link [6,7]. The existing scheme estimates the link quality with broadcasting a beacon message periodically. Further feedback control process helps to adapt controlled transmitting power. In acclimation of link quality for wireless network environment where environment variation exists, packet overhead for transmitting power control would be diminished. An important technique reduces the number of control packets and keeps retain reliability issues $[8,9,10]$. 
The contribution of this paper considers as the proposed scheme is based on two processes known as open loop and closed loop feedback. The open loop is used to calculate and compensate link quality due to different weather conditions. However closed-loop feedback process is used to divide the whole network into two logical regions to diminish the overload of packets. So that the transmitting power level to compensate the link quality and save the power to increase the lifetime of the sensor nodes.

The structure of the paper is organized as follow: Section 2, describes the proposed ETDCC reduction scheme is presented to lessen the losses and reduce the packet overhead. Simulation results and their discussions are presented in section 3 . Finally, we have concluded the paper in section 4 .

\section{Proposed Work}

In the current section, an energy efficient transmission scheme (ETDCC) has been proposed that maintains link quality according to variation in WSN. This scheme is designed for transmission power control dividing the network into two logical regions $(\mathrm{H}, \mathrm{L})$ and using openloop and closed-loop feedback process. The advantage of the open-loop and closed-loop process is to lessen overhead transmitting power significantly which is based on sensed snowfall rate information. The logical regions $\mathrm{H}$ and $\mathrm{L}$ denote high loss and low loss respectively on the basis of threshold loss.

ETDCC works into two phases i.e. initial phase and run-time phase. In the initial phase, a model is framed by each node for its respective neighbor link. While run-time phase, based on the division of network, retains the link quality with respect to time in the proposed scheme. In order to maintain the stability of network, the link quality is measured in initial phase to control overhead. Nevertheless the link quality is continuously varying in unstable network, initial phase is repeated and serious overhead takes place. In this scheme, the some parameters are expressed as follows: (i) Number of current neighbor nodes $n_{c}(t)$ (ii) Desired number of neighbor nodes $n_{d}(t)$. (iii) Error $e(t)=n_{d}(t)-n_{c}(t)$. (iv) Transmission power level ( $\left.p_{\text {level }}\right)$

To tune the transmission power, $\left(p_{\text {level }}\right)$ determines the connectivity with its neighbor nodes. The power controller calibrates transmission power level by comparing the number of initial neighbor nodes with the desired number of neighbor nodes. Loss and ACKs of a node are used to determine established link connectivity. ACK cannot determine the link quality but it can estimate the established link connectivity. The attenuation is used for connectivity estimation that estimates connectivity rather low overhead. The transmission power level has been adjusted by analyzing snowfall rate and number of current neighbor nodes. The close-loop operates not only to compare the number of initial neighbor nodes with desired nodes but also using snowfall compensated power level. Hence, the desired power level is obtained rapidly. If snowfall is changing then snowfall is compensated on the basis of connection between snowfall and attenuation. The low overhead maintains network connectivity by decreasing transmitting power among the nodes. This is possible due to division of regions in two parts where link quality is changing with snowfall variation. Due to snowfall variation, transmitting power loss is expressed using relationship between attenuation and snowfall. The snowfall attenuation has been classified into two categories known as dry and wet attenuation. The loss due to snowfall is expressed as follows [11]:

$$
A_{\text {snow }}(l o s s)[d B / k m]=a S^{b}
$$

Where, the parameters $a$ and $b$ for dry snow are

$$
a=5.42 * 10^{-5} \lambda+5.4958776, b=1.38
$$

And the parameters $a$ and $b$ for wet snow are

$$
a=1.023 * 10^{-4} \lambda+3.7855466, b=0.72
$$

where $\lambda$ is wavelength. 
To compensate estimated attenuation from equation (1), the output power of the transmitter should be controlled accordingly. The relationship between loss and required transmitter power level is expressed by equation (2) using least square approximation [12].

$$
P_{\text {level }}[\mathrm{dBm}]=\left[\frac{(\text { loss }+40)}{12}\right]^{2.91}
$$

With the help of equation (1) and (2), we have obtained the power level to compensate loss due to snowfall variation. Due to distance between each sensor node in WSN environment, path loss assists to calculate actual suitable transmitting power. After addition of power loss due to snowfall variation and distance given in equation (3), we calculate actual suitable transmitter power for all sensor nodes. In free space path loss model, following parameters are used- Number of nodes $(N)$, spectral efficiency $(\eta)$, required $\left(E_{b} / N_{o}\right)$ depends upon SNR, Boltzmann constant $(k)$, Bandwidth $(B)$, distance between each sensor node $(d)$, receiver noise figure $(R N F)$, frequency $(f)[13]$.

$$
P_{t}[d B m]=\left(\eta * \frac{E_{b}}{N_{0}} * k T B *\left(\frac{4 \pi d}{\lambda}\right)^{2}+R N F\right)+\text { loss }
$$

In this scheme, the main aim is to control the transmitting power by compensating loss variations based on snowfall changes sensed at each node. This scheme helps to gather information from snowfall sensor and does not need any communication overhead which is occurred due to neighbor nodes. The closed-loop feedback control complexity is reduced by open-loop control process significantly for transmitting power control. The some specific parameters are defined for this scheme as (1) Threshold loss for both regions, (2) Desired numbers of neighboring nodes in both regions, $n_{d}(t)=n_{c}(t)-5$, (3) Transmitting power level for both regions. Threshold loss should be minimum to retain link reliability. A beacon message is broadcast by reference node repetitively to neighboring nodes and ACKs is being waited. If ACKs are successfully delivered from neighbor nodes then Losses are calculated for both logical regions, high loss is considered in region $\mathrm{H}$ and low loss is considered in region L. If (loss $\geq$ lossthreshold) and ( $\left.N_{\text {current }} \geq N_{\text {desired }}\right)$ then threshold transmitter power level assigned if for the similar case $\left(N_{\text {current }}<N_{\text {desired }}\right)$ then similar transmitter power assigned and if (loss < lossthreshold) then by default keep same transmitter power level.

\section{Simulation Results and Discussions}

In this scheme, several measurements have been presented to estimate the availability of established link. The simulation results of proposed scheme are compared with the conventional approach for efficient power transmission in WSNs. In Figure 1 we have shown values of meteorological snowfall loss and transmission power loss for one round that is sensed by each sensor node in WSNs. It is considered that 100 nodes are randomly deployed in $100 x 100 \mathrm{~m}^{2}$ area and snowfall rate have values in the range $(1$ to 10$) \mathrm{mm} / \mathrm{hr}[11]$ for meteorological weather condition. The reference node has been placed at the edge of considered region. The Figure 1 depicts nodes and snowfall variation on $\mathrm{x}$-axis and $\mathrm{y}$-axis respectively. The sensor nodes are randomly placed in considered area and respective variation in snowfall rate can be seen for different nodes in WSNs. The value of Snowfall rate for all sensor nodes, based on meteorological weather conditions, is used to calculate power loss $(\mathrm{dBm})$ that is expressed as transmitting power loss. Sensed snow $_{\text {wet }}$ and transmitting power losses have been depicted in Figure 2 for each sensor node. High $(\mathrm{H})$ transmitting power loss $(\mathrm{dBm})$ means that the snowfall rate of sensor nodes, placed in the considered region, is high. It represents that the established links do not have good quality.

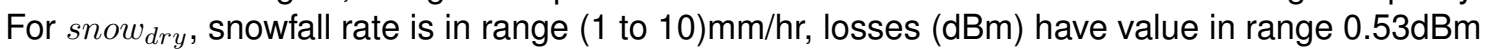
to $11.38 \mathrm{dBm}$. For snow $_{\text {wet }}$, snowfall rate is in range $0.4 \mathrm{~mm} / \mathrm{hr}$ to $1.8 \mathrm{~mm} / \mathrm{hr}$, losses occur between $0.35 \mathrm{dBm}$ to $1.72 \mathrm{dBm}$. The several simulation parameters are presented here such as round $(\mathrm{r})$ 1500, distance (1-87)m, nodes(N) 100, Regions H and L, $\eta$ 0.0029, Signal to Noise Ratio (SNR) $0.20 \mathrm{~dB}$, frequency $(f) 2.45 \mathrm{GHz}, R N F 5 \mathrm{~dB}$, Bandwidth $(B) 83.5 \mathrm{MHz}$, and ratio of energy per bit to the spectral noise $\left(E_{b} / N_{o}\right) 8.3 \mathrm{~dB}$.

TELKOMNIKA Vol. 16, No. 3, June $2018: 1126 \sim 1134$ 

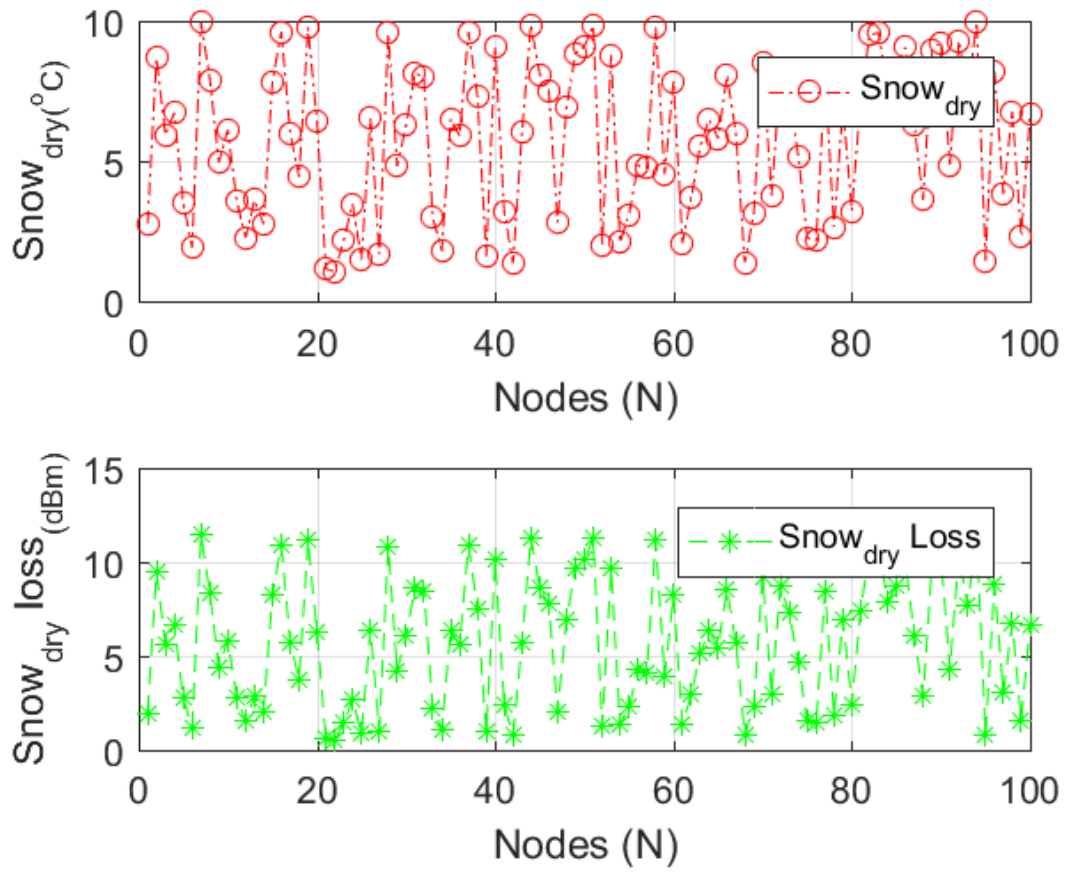

Figure 1. Sensed snow dry $_{\text {rate }}$ and snow sry $_{\text {loss for nodes }}$
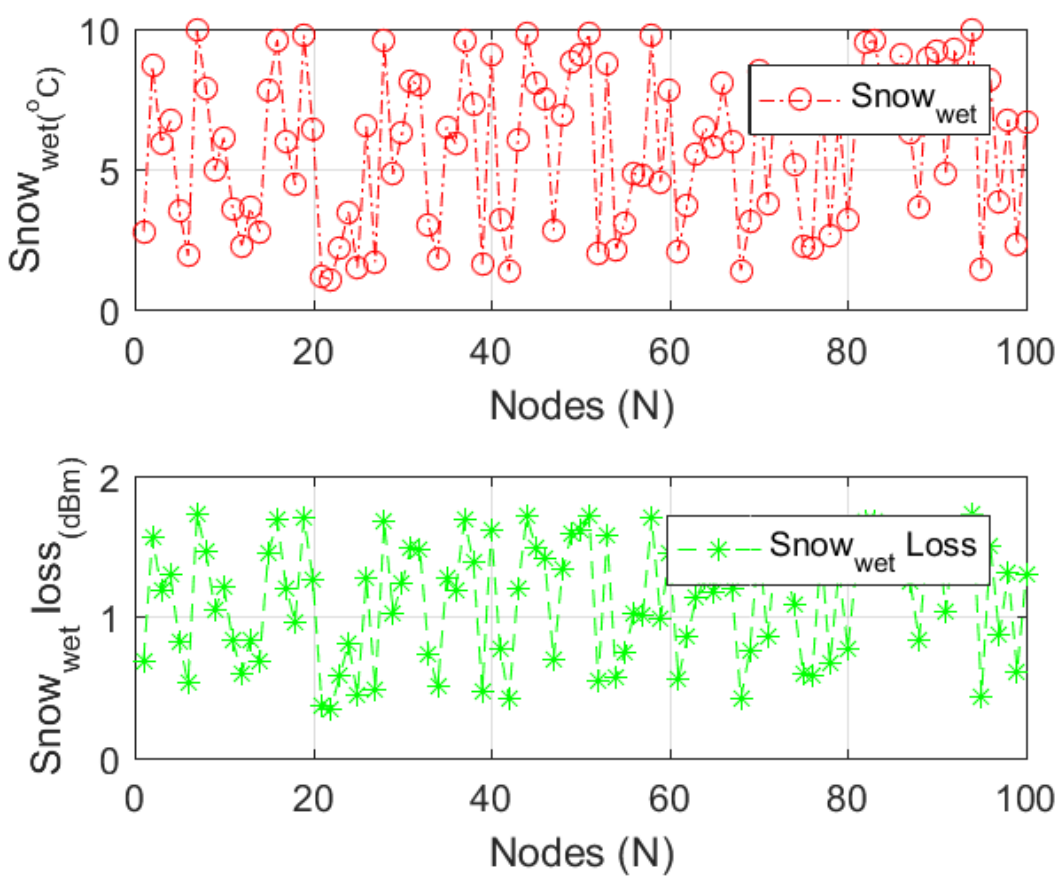

Figure 2. Sensed snow $w_{\text {wet }}$ rate and snow wet $_{\text {loss for nodes }}$ 


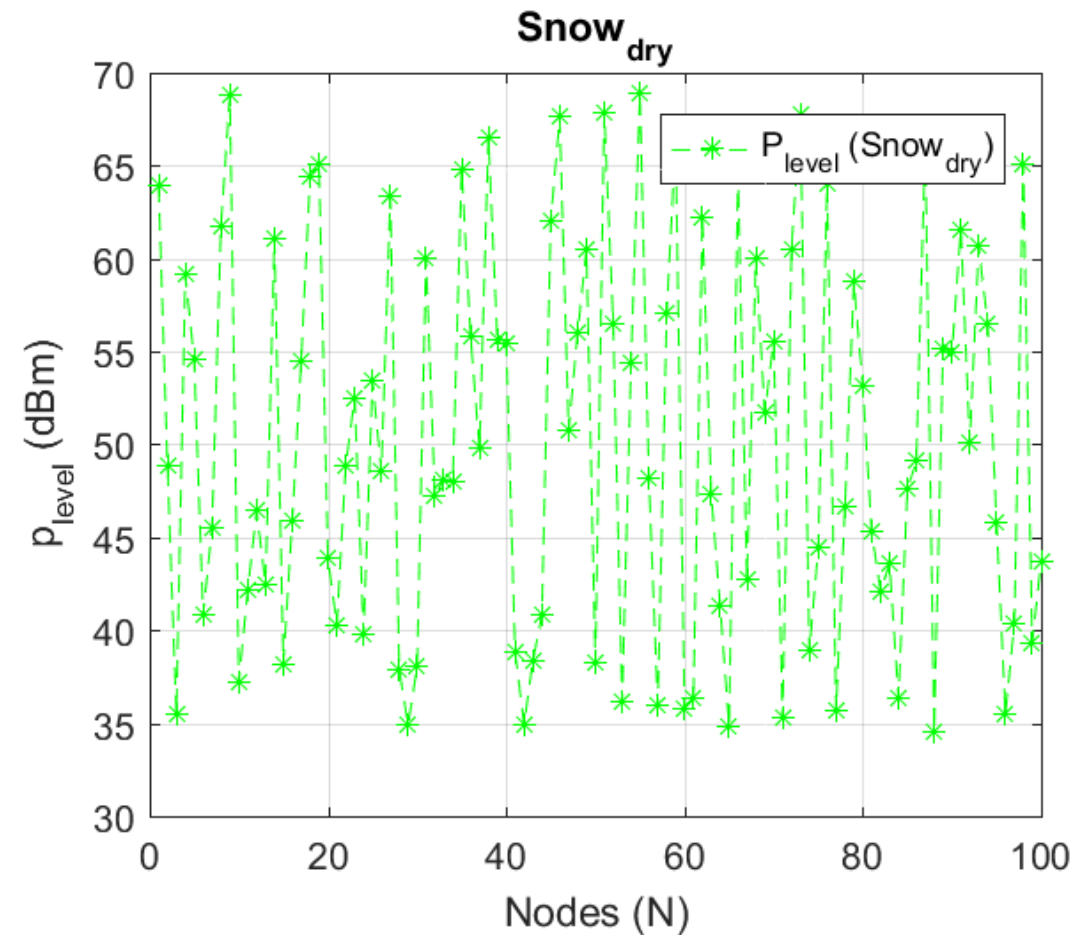

Figure 3. $\mathrm{P}_{\text {level }}\left(\right.$ snow $\left._{\text {dry }}\right)$ for nodes

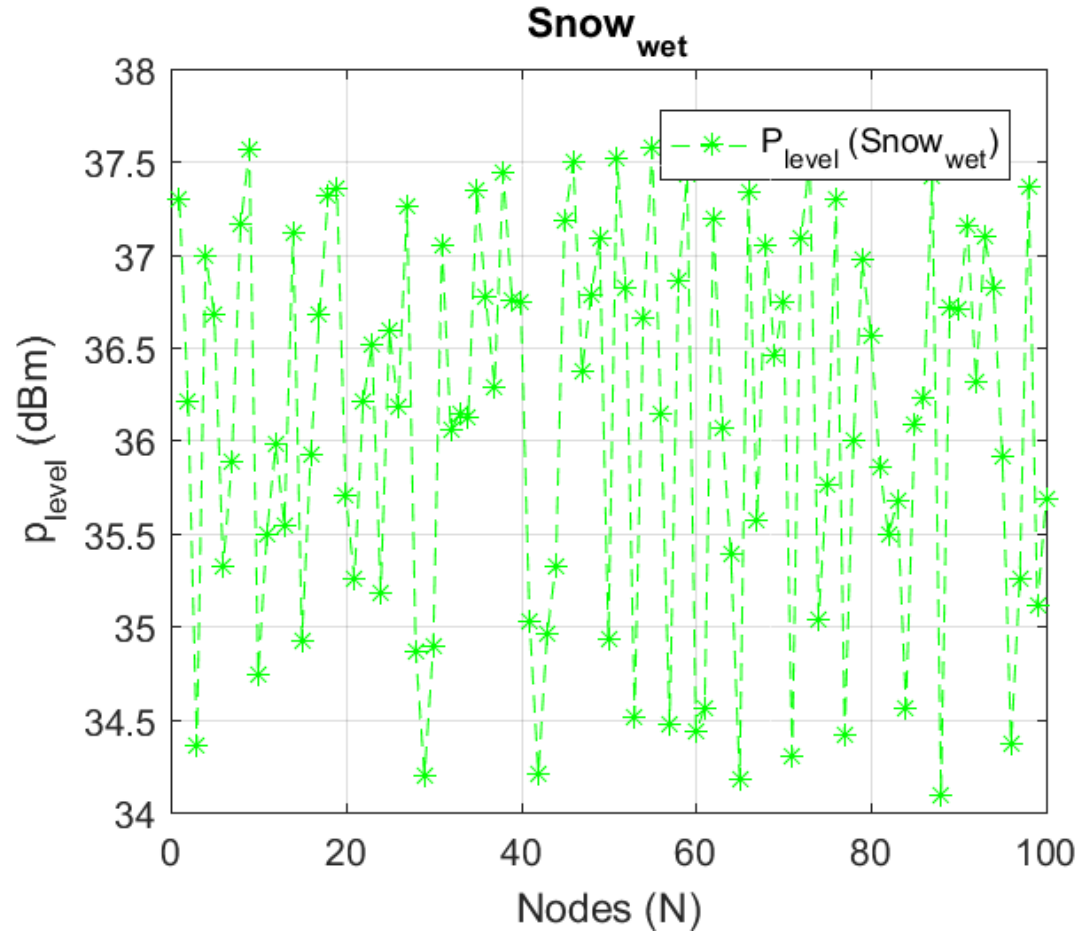

Figure 4. $\mathrm{P}_{\text {level }}\left(\mathrm{snow}_{\text {wet }}\right)$ for nodes 


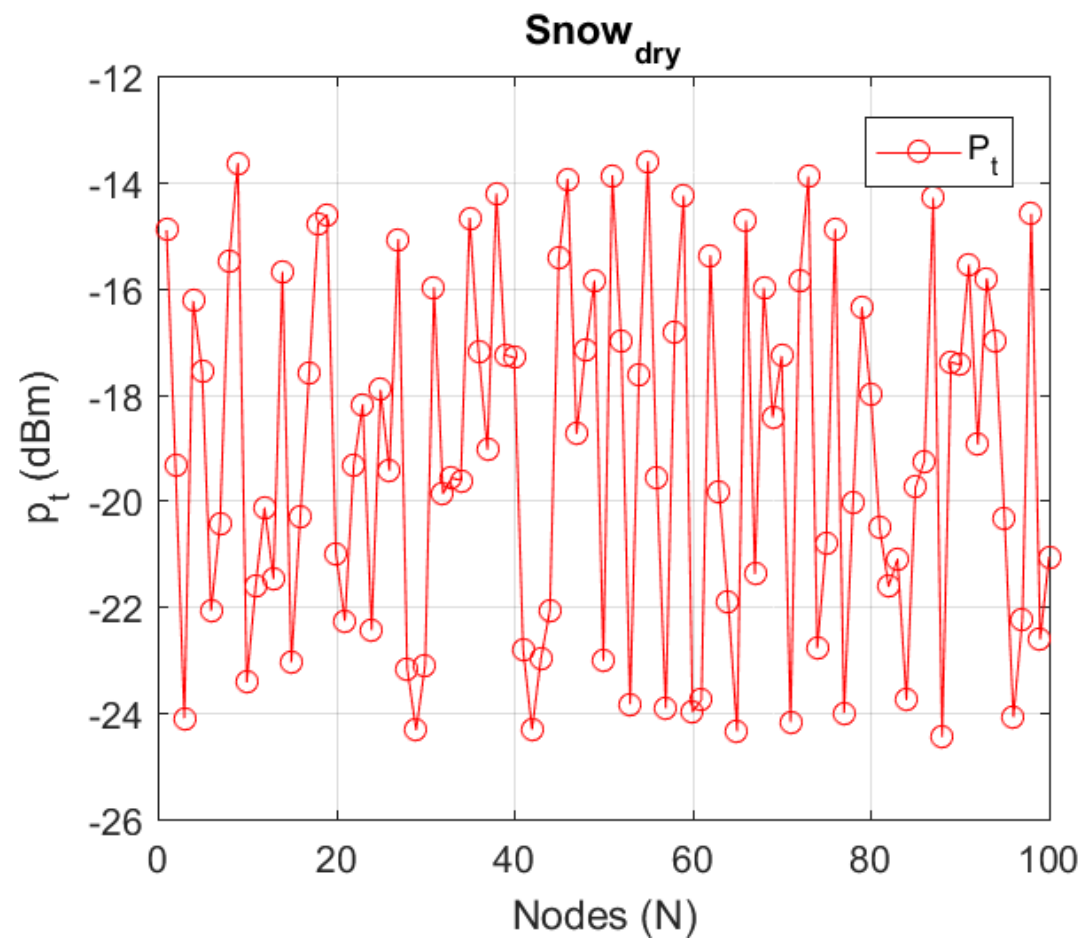

Figure 5. $P_{t}\left(\right.$ snow $\left._{d r y}\right)$ for nodes

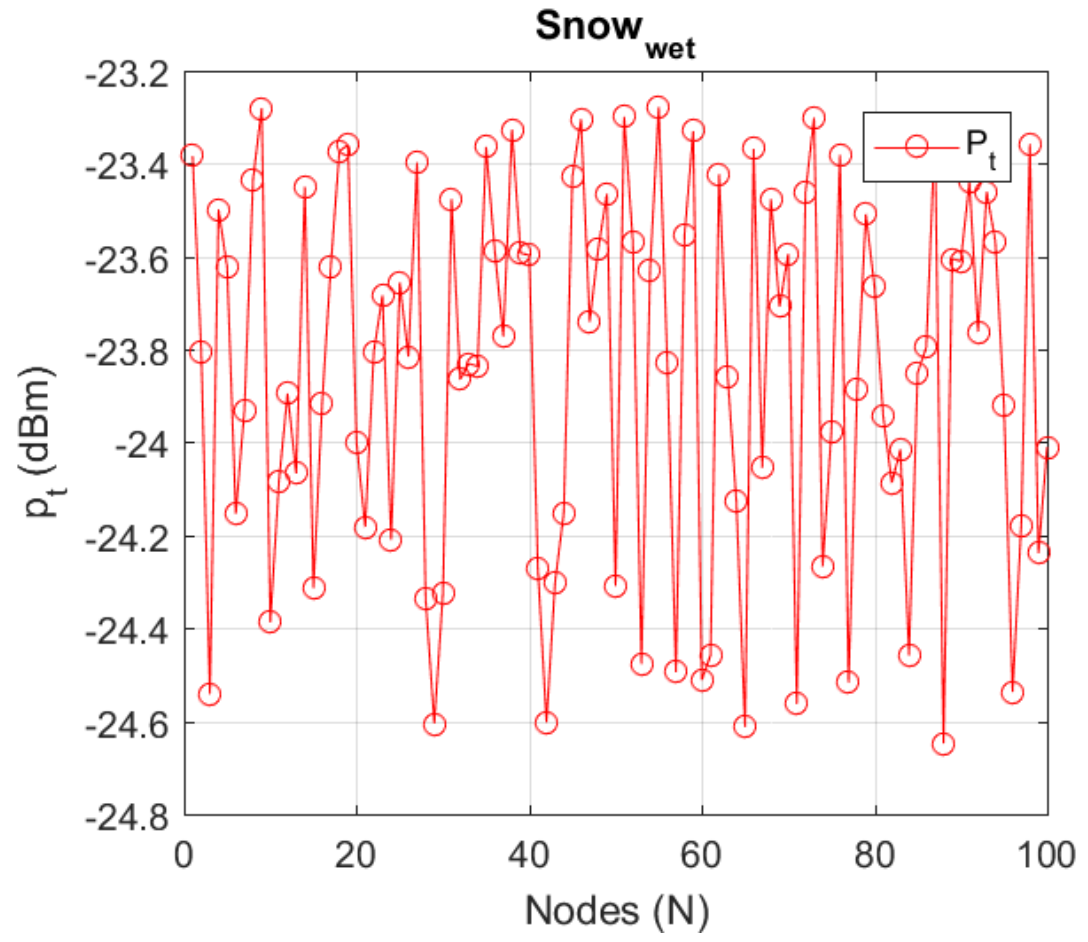

Figure 6. $P_{t}\left(\right.$ snowet $\left._{\text {wet }}\right)$ for nodes 

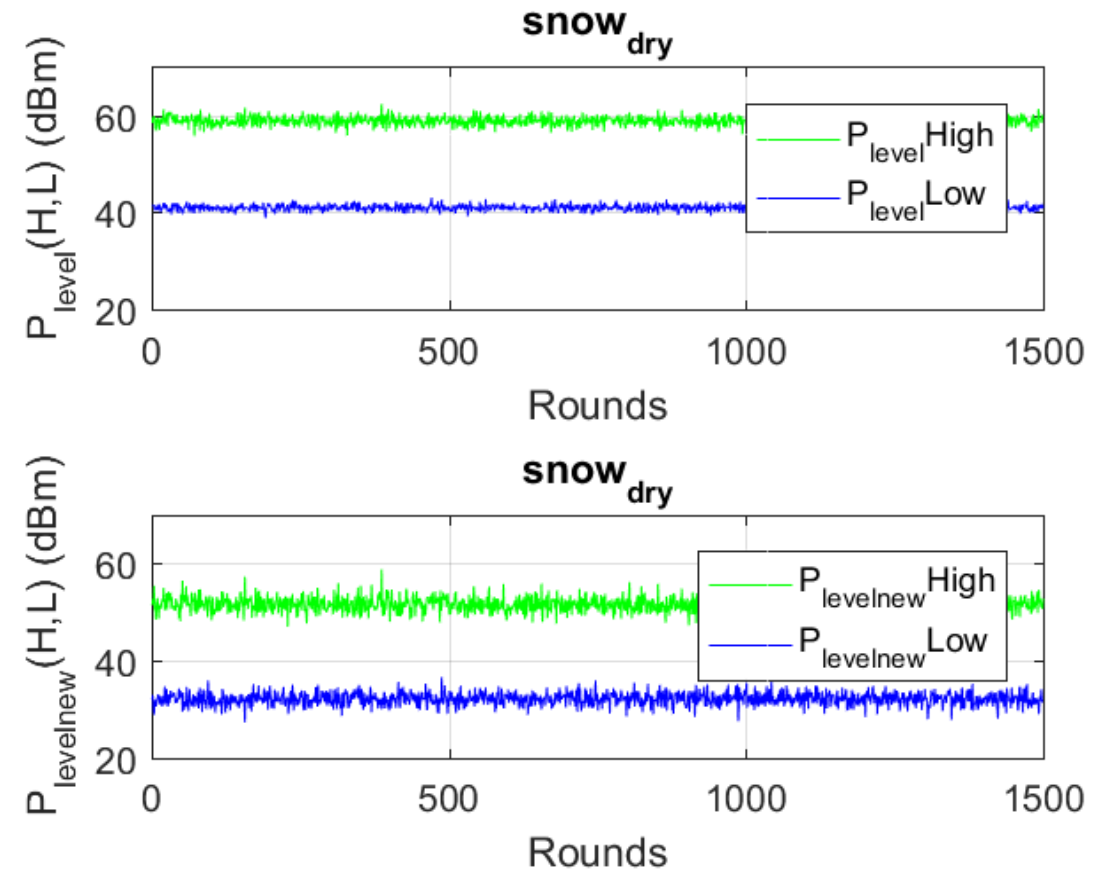

Figure 7. $P_{\text {level }}\left(\right.$ snow $\left._{\text {dry }}\right)$ using conventional and ETDCC scheme for nodes
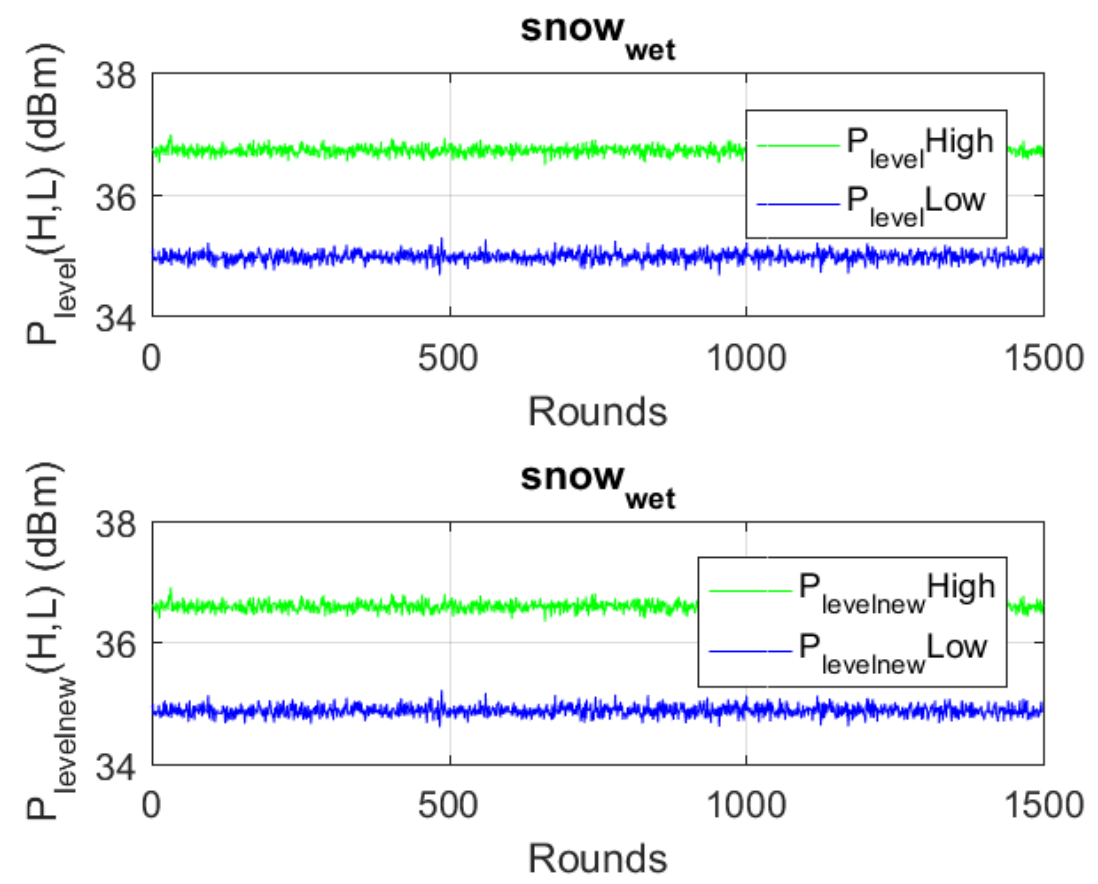

Figure 8. $P_{\text {level }}\left(\right.$ snow $\left._{w e t}\right)$ using conventional and ETDCC scheme for nodes 
Table 1. Estimated parameters for single round

\begin{tabular}{|l|l|l|}
\hline Parameter & \multicolumn{2}{|c|}{ Value } \\
\hline & snow ${ }_{\text {dry }}$ & snow wet \\
\hline $\mathrm{N}(\mathrm{H}, \mathrm{L})$ & 54,46 & 52,48 \\
\hline Desired neighbors $(\mathrm{H}, \mathrm{L})$ & 49,41 & 47,43 \\
\hline Current neighbors $(\mathrm{H}, \mathrm{L})$ & 47,38 & 45,40 \\
\hline Threshold $P_{\text {level }}(\mathrm{H}, \mathrm{L})$ & $41.79,58.19$ & $36.65,35.07$ \\
\hline Nodes above the threshold loss $(\mathrm{H}, \mathrm{L})$ & 25,22 & 24,23 \\
\hline Nodes below the threshold loss $(\mathrm{H}, \mathrm{L})$ & 18,17 & 19,16 \\
\hline Threshold loss $(\mathrm{H}, \mathrm{L})$ & $3.07,2.83$ & $1.38,0.72$ \\
\hline
\end{tabular}

From Figure 1 and Figure 2, it can be seen that the power loss and link quality have an inverse relation and when snowfall rate increases, loss increases. Hence, It concludes that there is low link quality at higher snowfall rate and vice versa. So, the link quality is better at small snowfall rate. After estimating the power loss for each sensor, we calculate their transmitting power level to compensate the loss. Figure 3 and Figure 4 present the range of power level for variation of power loss on $\mathrm{y}$-axis that is $34.53 \mathrm{dBm}$ to $68.88 \mathrm{dBm}$ for snow $w_{d r y}$ and $34.10 \mathrm{dBm}$ to $37.6 \mathrm{dBm}$ for snowet. The power level of sensor node is changing according to snowfall variation, i.e. the low power level is required at low snowfall rate and vice versa. The power level ( power $_{\text {level }}$ ) of each sensor node has been compensated on the basis of snowfall rate to compensate the transmitting power loss. In WSNs, the path loss occurs due to distance and snowfall variation between each sensor node. A free space model helps to calculate the transmitter power $\left(p_{t}\right)$. After calculation of power level due to snowfall variation and distance, we calculate required transmitter power comprising transmitting power loss due to snowfall rate and free space path loss for all nodes. Figure 5 and Figure 6 depict the transmitter power range on $\mathrm{y}$-axis that is $-24.47 \mathrm{dBm}$ to $-13.62 \mathrm{dBm}$ for snow dry and $-24.70 \mathrm{dBm}$ to $-23.3 \mathrm{dBm}$ for snow wet.

Further the network is divided in two logical regions $(\mathrm{H}, \mathrm{L})$ for the analysis of proposed scheme. In the simulations, we have taken 1500 rounds for analysis. Table 1 shows the estimated parameters for single round based on loss and threshold loss for each region. The threshold power levels have been estimated for both logical regions. Losses are calculated and described transmitting power loss due to snowfall variations. After sensed snowfall at each node, we have assigned the loss to each node.

On the basis of threshold loss for both logical regions, number of nodes are counted for each region. Nodes have high loss in region $(\mathrm{H})$ and low loss in region $(\mathrm{L})$.

Table 2. Comparision of proposed technique to conventional technique

\begin{tabular}{|l|l|l|}
\hline Climatic region & $P_{\text {level }}(\mathrm{dBm})$ & $P_{\text {levelnew }}(\mathrm{dBm})$ \\
\hline Snow $_{\text {dry }}(\mathrm{H})$ & 58.1807 & 50.8787 \\
\hline Snow $_{\text {dry }}(\mathrm{L})$ & 40.2114 & 31.9903 \\
\hline Snow $_{\text {wet }}(\mathrm{H})$ & 36.7412 & 36.6419 \\
\hline Snow $_{\text {wet }}(\mathrm{L})$ & 35.0116 & 34.8585 \\
\hline
\end{tabular}

After calculating losses of nodes in both regions, the power level is calculated for each node in each region that are clearly shown in Figure 7 and Figure 8. Through Figure 7 and Figure 8 , the difference between conventional power level and proposed power level $\left(P_{\text {newlevel }}\right)$ can be seen clearly for $s n o w_{d r y}$ and $s n o w_{w e t}$. From Figure 7 and Figure 8, it is clear the required power level decreases in both regions. The proposed scheme achieves that the transmission power loss is better than the conventional transmission power loss. 


\section{Conclusion}

This paper has provided a scheme ETDCC to determine snowfall effect on the node link quality. The snowfall is the significant factor that affects the variation of link quality. The connection between attenuation and snowfall have been evaluated for transmitting power control of nodes. The open-loop system is used to compensate the change of link quality according to snowfall variation. However, close-loop feedback has minimized the overhead of transmitting power control in WSNs which is helpful to adjust the transmitting power according to the variation of link quality and thus, the network lifetime is enhanced significantly. The simulation results conclude that the power level for high and low region is reduced more than $13 \%$ and $23 \%$ respectively with respect to conventional approach. In future, the power level can be estimated considering sensor nodes movement for different weather conditions.

\section{References}

[1] M. Tahir, N. Javaid, Z. A. Khan, U. Qasim, and M. Ishfaq, "East: Energy-efficient adaptive scheme for transmission in wireless sensor networks," in Electrical and Computer Engineering (CCECE), 2013 26th Annual IEEE Canadian Conference on. IEEE, 2013, pp. 1-4.

[2] M. Alhilali, J. Din, M. Schönhuber, and H. Y. Lam, "Estimation of millimeter wave attenuation due to rain using $2 \mathrm{~d}$ video distrometer data in malaysia," Indonesian Journal of Electrical Engineering and Computer Science, vol. 7, no. 1, pp. 164-169, 2017.

[3] F. Lavratti, A. Ceratti, D. Prestes, A. Pinto, L. Bolzani, F. Vargas, C. Montez, F. Hernandez, E. Gatti, and C. Silva, "A transmission power self-optimization technique for wireless sensor networks," ISRN Communications and Networking, vol. 2012, p. 1, 2012.

[4] M. H. Misran and S. K. A. Rahim, "Optimum transmitter receiver ratio for maximum wireless energy transfer," Indonesian Journal of Electrical Engineering and Computer Science, vol. 5, no. 3, pp. 599-605, 2017.

[5] V. G. Douros and G. C. Polyzos, "Review of some fundamental approaches for power control in wireless networks," Computer Communications, vol. 34, no. 13, pp. 1580-1592, 2011.

[6] T. Rashid, S. Kumar, and A. Kumar, "Reer: Relay based energy efficient routing for intra body sensor network (intra-wbsn)," in Signal Processing and Integrated Networks (SPIN), 2017 4th International Conference on. IEEE, 2017, pp. 222-227.

[7] R. Karthik, J. Nagaraju, and M. Vucha, "Distributed optimal relay selection in wireless sensor networks," Indonesian Journal of Electrical Engineering and Computer Science, vol. 7, no. 1, pp. 71-74, 2017.

[8] N. A. Latiff, M. Ruslee, S. S. Yusof, M. A. Rahim, H. Sayuti, K. M. Yusof, and M. Baharudin, "A training monitoring system for cyclist based on wireless sensor networks," Indonesian Journal of Electrical Engineering and Computer Science, vol. 6, no. 1, pp. 80-87, 2017.

[9] A. M. D. Masood and S. Muthusundar, "Load balance: Energy efficient routing protocol in wireless sensor network," Indonesian Journal of Electrical Engineering and Computer Science, vol. 9, no. 3, 2018.

[10] S. Saravanan, "Efficient and energy scheme for wireless rechargeable sensor network," Indonesian Journal of Electrical Engineering and Computer Science, vol. 9, no. 2, 2018.

[11] F. Nadeem, S. Chessa, E. Leitgeb, and S. Zaman, "The effects of weather on the life time of wireless sensor networks using fso/rf communication." Radioengineering, vol. 19, no. 2, 2010.

[12] K. Bannister, G. Giorgetti, and S. K. Gupta, "Wireless sensor networking for hot applications: Effects of temperature on signal strength, data collection and localization," in Proceedings of the 5th Workshop on Embedded Networked Sensors (HotEmNets 08). Citeseer, 2008.

[13] M. Tahir, N. Javaid, A. Iqbal, Z. A. Khan, and N. Alrajeh, "On adaptive energy-efficient transmission in wsns," International Journal of Distributed Sensor Networks, vol. 9, no. 5, p. 923714, 2013. 